\title{
The Impact of Covid-19 Spread on Stock Markets: The Case of the GCC Countries
}

\author{
Nader Alber ${ }^{1}, \&$ Amr Saleh ${ }^{2}$ \\ ${ }^{1}$ Professor of Finance, Ain Shams University, Cairo, Egypt \\ ${ }^{2}$ Associate Professor of Economics Ain Shams University, Cairo, Egypt \\ Correspondence: Nader Alber, Ain Shams University, Cairo, Egypt.
}

Received: July 28, 2020

doi:10.5539/ibr.v13n11p16
Accepted: October 14, 2020

Online Published: October 21, 2020

URL: https://doi.org/10.5539/ibr.v13n11p16

\begin{abstract}
This paper attempts to investigate the effects of 2020 Covid-19 world-wide spread on stock markets of GCC countries. Coronavirus spread has been measured by cumulative cases, new cases, cumulative deaths and new deaths. Coronavirus spread has been measured by numbers per million of population, while stock market return is measured by $\Delta$ in stock market index.

Papers conducted in this topic tend to analyze Coronavirus spread in the highly infected countries and focus on the developed stock markets. Countries with low level of infection that have emerging financial markets seem to be less attractive to scholars concerning with Coronavirus spread on stock markets. This is why we try to investigate the GCC stock markets reaction to Covid-19 spread.

Findings show that there are significant differences among stock market indices during the research period. Besides, stock market returns seem to be sensitive to Coronavirus new deaths. Moreover, this has been confirmed for March without any evidence about these effects during April and May 2020.
\end{abstract}

Keywords: Coronavirus, COVID-19, stock market return, GMM technique, panel analysis

\section{Introduction}

The $20^{\text {th }}$ century witnessed two pandemics since the historic Spanish Influenza of 1918, the Asian flu of 1957 and the Hong Kong flu of 1968. The $21^{\text {st }}$ century has seen four pandemic outbreaks: bird flu (NIHI) in 2009, Severe Acute Respiratory Syndrome (SARS) in 2002, Middle East Respiratory Syndrome (MERS) in 2012, and Ebola in 2013 (Baldwin \& Weder di Mauro, 2020, p. 5).

Usually, global financial crisis plays out in countries across the globe and consequently manifests in four overlapping phases. Although each phase has a policy focus, each phase of the crisis affects the others, and, until the crisis has passed, no phase seems to have a clear end point. Nanto (2009) summarized the four phases of the global financial crisis as follows: contain the contagion and strengthen financial sectors; coping with macroeconomic effects; regulatory and financial market reform and dealing with political, social, and security effects. Orlweski (2008) identifies five distinctive stages of the current global financial crisis as follows: the outbreak of the subprime mortgage crisis; the proliferation of credit risk, with the broadening of losses of financial institutions; the eruption of liquidity crisis; the commodity price bubble and the ultimate freeze of credit markets.

When it comes to COVID- 19, it's important to consider not only the characteristics of financial crisis, but also the economic shocks, where poverty kills poor people, but the outbreak of COVID-19 has another story. McKibbin \& Fernando (2020) shows that if diseases are generated in poor countries due to overcrowding, poor public health and interaction with wild animals, they can kill people of any socioeconomic group in any society. Unfortunately, politicians continue to ignore the needs of investment in public health and development and the scientific evidence on the role of public health in improving the quality of life and as a driver of economic growth.

Coronavirus spread has been increased during the research period in all of the GCC countries, where Saudi Arabia has recorded the highest indicators and Bahrain has registered the lowest ones (https://www.worldometers.info/coronavirus). 
Figure (1) shows the developments of GCC stock markets' indices, as follows:

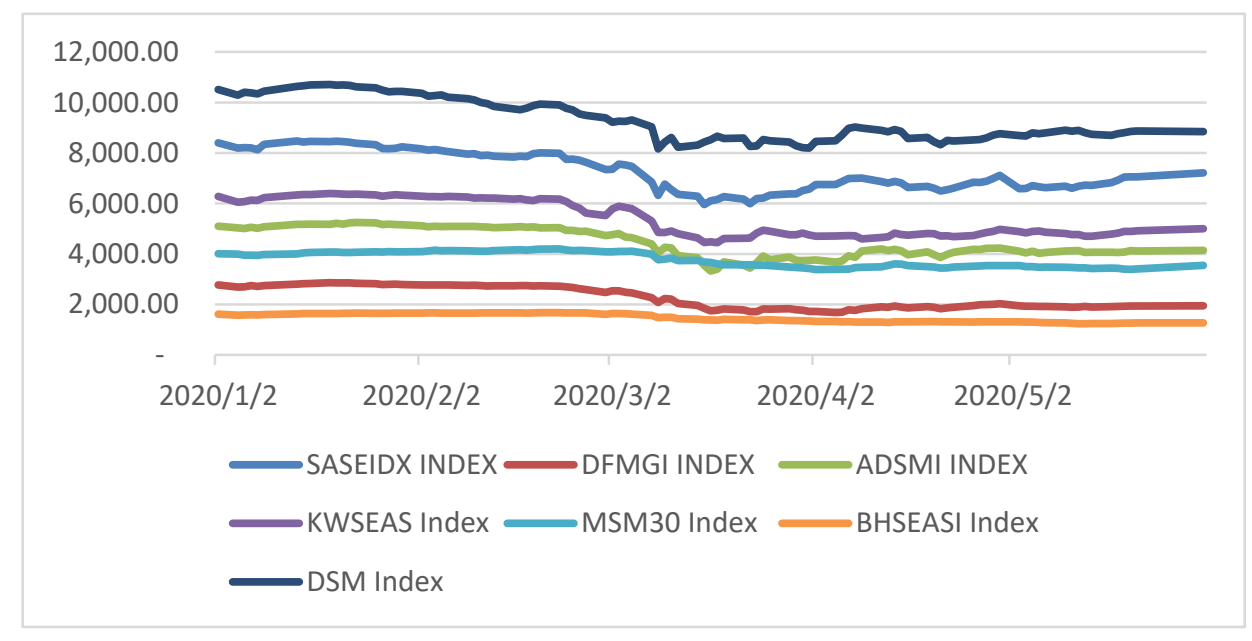

Figure 1. Development of GCC Stock Markets' Indices

Figure (1) shows that stock market returns tend to be decreasing during March 2020 and seem to be flattened during April and May. This paper tries to explain the behavior of stock market returns due to Coronavirus spread indicators.

This paper addresses a main question about the stock market reaction to Coronavirus spread. This has been applied on the Gulf Cooperation Council (GCC) countries, on daily basis over the period from March 1, 2020 till May 31, 2020. So, this paper tries to address the following questions:

1- Are there significant differences among stock market indicators during months of Coronavirus spread compared with the earlier months.

2- Does Coronavirus spared affect stock market return?

After this introduction, section 2 illustrates the related literature. Section 3 explains how to develop hypotheses and measure variables. Section 4 presents descriptive and diagnostic statistics. Section 5 is for testing hypotheses and section 6 is for robustness checks. Section 7 summarizes the paper and provides remarks about conclusions.

\section{Literature Review}

This section tries to present some of previous work, which has been conducted in the field of stock market reaction to the positive or negative informational contents, especially to the announcement about Coronavirus spread. Besides, it covers some recent papers about Coronavirus economic effects.

Stock markets seem to be sensitive to bad news and this sensitivity may differ according to countries and industries, where Alber (2013a) supports the effects of "industry effect" on stock market reaction to global financial crisis in Egyptian, Kuwaiti, American and British stock markets during the period from 2007 to 2011. Besides, Saleh (2017) shows that the factors of fears and hesitation to startup an investment is one of the most important factor that brings entrepreneurs to fail in their investments, comparing with the institutional or individual investors in the stock market, where the brokers absorb the psychological fears and chocks.

On the other hand, good news may affect stock market returns, where Alber (2013b) addresses the effects of quality announcement on performance Egyptian listed companies. This has been conducted using a sample of 11 events, covering announcements of international and national quality accreditation during the period from 2006 to 2012. Using event study methodology, results indicate that, hypotheses regarding the significance of differences between ARs and CARs could be accepted. Another study by Alber (2020a) attempts to investigate the effects of Coronavirus spread on stock markets of the worst 6 countries over the period from March 1, 2020 till April 10, 2020. Results indicate that stock market return seems to be sensitive to Coronavirus cumulative cases. Besides, robustness check confirms these effects for China, France, Germany and Spain. However, these effects haven't been confirmed for Italy and United States. Using the same indicators of Coronavirus spread in Belgium, France, Germany, Italy, Netherlands Spain and UK, Alber (2020b) has NOT supported the anticipated effects during the period from Febreuary15, 2020 till May 24, 2020 on daily basis. After splitting the research 
period into 7 sub-periods (2-weeks each), results indicate that abnormal return of stock market seems to be sensitive to Coronavirus cumulative cases. This has been applied using panel analysis according to GMM technique.

Yan (2020) examines how COVID-19 affects Chinese stock markets from January 20, 2020 till April 7, 2020. The results show that the coronavirus leads the stock prices to fall sharply. Other studies have been conducted to assess the effects of Coronavirus spread globally, where Rehan, Alvi, \& Karaca (2020) checks the short term stress of COVID-19 on the American, European, Asian, and Pacific stock market indices, using data of 41 stock exchange from 32 countries from 1st July 2019 to 14th May 2020. Results show that there is a significant negative relationship between the number of COVID-19 cases and the stock indices. Besides, Liu, Manzoor, Wang, Zhang \& Manzoor (2020) indicates that there is a negative relationship between the increase in the number of cases and stock indices return of 21 major stock indices. Findings show that Asian countries are more affected than the other regions.

Many papers focus on market reaction to Coronavirus spread in terms of "industry effect", where Mazur, Dang \& Vega (2020) investigates the US stock market performance during the crash of March 2020 triggered by COVID-19, using the Standard and Poor's 1,500 firms during March 2020. Finding show that natural gas, food, healthcare, and software stocks earn high positive returns, whereas equity values in petroleum, real estate, entertainment, and hospitality sectors fall dramatically. Moreover, Yan, Stuart, Tu \& Zhang (2020) indicates that shorting travel stocks, entertainment stocks, and certain technology stocks, are likely ways to make short term profit due to the short-term panic selloff caused by the coronavirus outbreak. The study suggests purchasing a gold ETF because gold performs well in volatile markets and predicts that because the market is still volatile, there is still room for the price of stocks to keep decreasing. Besides, Kandil Goker, Eren, \& Karaca (2020) investigates impact of the COVID-19 outbreak on the Borsa Istanbul sector index returns. This study reveals the impact of the pandemic on sector basis. The data of 26 sectors in BIST are analyzed by the event study. Results indicate that most of the sectors have negative cumulative abnormal returns and the highest lost is found in the Sports, Tourism and Transportation sectors.

Regarding economic effects of Coronavirus spread, McKibbin \& Fernando (2020) has presented some preliminary estimates of the cost of the COVID-19 outbreak under seven different scenarios of how the disease might evolve. In the short term, central banks and Treasuries need to make sure that disrupted economies continue to function while the disease outbreak continues. The longer-term responses are even more important. Besides, Gormsen \& Koijen (2020) tries to quantify how investors' expectations about economic growth across horizons evolve in response to the coronavirus outbreak and subsequent policy responses. As of March 25, the forecast of annual growth in dividends is down $28 \%$ in the US and $22 \%$ in the EU, while their forecast of GDP growth is down by $2.2 \%$ in the US and $2.8 \%$ in the EU.

Comparing with literature, it's important to pinpoint that it considers not only both of infection and death indicators, but also, both of cumulative and new ones. Moreover, Coronavirus spread has been measured relatively, where all measures are adjusted per million of country population. Besides, this study focuses on GCC countries, while many studies concern with the US, China and Europe.

\section{Measuring Variables and Developing Hypotheses}

Coronavirus spread has been measured by "Cumulative Coronavirus Cases" (CCC), "Cumulative Coronavirus Deaths" (CCD), "New Coronavirus Cases" (NCC) and "New Coronavirus Deaths" (NCD), on daily basis, in terms of country population. Stock market return is measured by $\Delta$ in stock market index. Data about Coronavirus are obtained from: https://www.worldometers.info/coronavirus and research variables are calculated as follows:

$$
\mathrm{SMR}=\Delta \text { of market index } m \text { at the end of day } n
$$

$$
\text { CCC = Ln of Cumulative Coronavirus Cases (per million of population) }
$$

CCD = Ln of Cumulative Coronavirus Deaths (per million of population)

$$
\text { NCC }=\text { Ln of New Coronavirus Cases (per million of population) }
$$

$$
\text { NCD = Ln of New Coronavirus Deaths (per million of population) }
$$

This paper aims at testing the following two hypotheses:

1- There's no significant differences among stock market indicators during months of Coronavirus spread compared with the earlier months.

2- There's no significant effect of "Coronavirus spread" on "stock market return". 
Regarding the first hypothesis, Wilcoxon Signed Rank test has been conducted to investigate the significance of differences among stock market indicators during March, April and May 2020 compared with the January and February 2020.

Regarding the second hypothesis, we consider the alternative hypothesis Ha: $\beta$ \# 0 versus null hypothesis $\mathrm{Hb}: \beta$ $=0$, where $\beta$ is the regression coefficient of the following functions:

$$
\begin{array}{r}
\mathrm{SMR}=\alpha+\beta \mathrm{CCC}+\varepsilon \\
\mathrm{SMR}=\alpha+\beta \mathrm{NCC}+\varepsilon \\
\mathrm{SMR}=\alpha+\beta \mathrm{CCD}+\varepsilon \\
\mathrm{SMR}=\alpha+\beta \mathrm{NCD}+\varepsilon
\end{array}
$$

All of the Coronavirus indicators are positively correlated and this is why we test their effects separately to avoid the problem of multicollinearity.

\section{Descriptive and Diagnostic Statistics}

The first COVID-19 cases in Europe were reported in UAE, on February 15, 2020, and the first death was in Bahrain on March 16, 2020. Tables (2) illustrates the information of the research sample that includes 7 stock markets, over the period from March 1, 2020 till May 31, 2020 as follows:

Table 1. Sample information

\begin{tabular}{|l|l|}
\hline \multicolumn{1}{|c|}{ Country } & \multicolumn{1}{c|}{ Stock index } \\
\hline Saudi Arabia & Tadawul All Share Index (SASEIDX) \\
\hline UAE (Dubai) & Dubai Financial Market General Index (DFMGI) \\
\hline UAE (Abu Dhabi) & Abu Dhabi Securities Market General Index (ADSMI) \\
\hline Kuwait & Kuwait Stock Exchange Index (KWSEAS) \\
\hline Oman & Muscat Securities MSM 30 Index (MSM30) \\
\hline Bahrain & Bahrain Bourse All Share Index (BHSEASI) \\
\hline Qatar & Qatar Exchange Index (formerly DSM20 Index) \\
\hline
\end{tabular}

Tables (2) illustrates descriptive statistics of the research variables during the research period and table (3) indicates the correlation coefficients as follows:

Table 2. Descriptive statistics of research variables

\begin{tabular}{|l|c|c|c|c|c|}
\hline Variables & SMR & CCC & CCD & NCC & NCD \\
\hline Mean & 0.002817 & 6.646677 & 1.545638 & 3.795369 & -1.103376 \\
\hline Median & 0.002711 & 6.821536 & 1.665298 & 3.927035 & -1.192953 \\
\hline Maximum & 0.063835 & 9.891070 & 3.904839 & 6.349162 & 0.850838 \\
\hline Minimum & -0.074136 & 3.092471 & -3.550016 & 0.934410 & -3.550016 \\
\hline Std. Dev. & 0.018168 & 1.304635 & 1.321451 & 1.052671 & 0.790403 \\
\hline Skewness & -0.087023 & -0.561700 & -0.826492 & -0.495304 & -0.097431 \\
\hline Kurtosis & 4.755148 & 3.119817 & 3.953882 & 3.503981 & 3.492638 \\
\hline Jarque-Bera & 25.01630 & 10.26425 & 29.28977 & 9.933863 & 2.257000 \\
\hline Probability & 0.000004 & 0.005904 & 0.000000 & 0.006964 & 0.323518 \\
\hline Observations & 193 & 193 & 193 & 193 & 193 \\
\hline
\end{tabular}

Source: Outputs of data processing using EViews 10. 
Table 3. Correlation coefficients between research variables

\begin{tabular}{|l|c|c|c|c|c|}
\hline & SMR & CCC & CCD & NCC & NCD \\
\hline SMR & 1.00000 & & & & \\
\hline CCC & -0.08375 & 1.00000 & & & \\
\hline NCC & -0.13325 & 0.90213 & 1.00000 & & 1.00000 \\
\hline NCD & -0.05397 & 0.93389 & 0.79454 & 0.62168 & 1.00000 \\
\hline NCD & -0.14266 & 0.65501 & 0.66503 & & \\
\hline
\end{tabular}

Source: Outputs of data processing using EViews 10.

Regarding normality, Jarque-Bera values indicate that all variables are normally distributed at $\mathrm{p}$-value of 0.01 for most of the research variables. Regarding multicollinearity, the correlation coefficients among independent variables range from 0.62168 to 0.93389 , which indicates that multicollinearity problem does exist and this is why we will use these variables separately.

\section{Testing Hypotheses}

The first hypothesis is about investigating the significance of differences between average changes in sector indices of stock markets, according to month of analysis. The null hypothesis $\mathrm{H}_{0}$ could be shown as:

$$
\mu \text { SMR-JAN }=\mu \text { SMR-FEB }=\mu \text { SMR-MAR }=\mu \text { SMR-APR }=\mu \text { SMR-MAY }
$$

The alternative hypothesis $\mathrm{H}_{\mathrm{a}}$ states that:

$$
\mu_{\text {SMR-JAN }} \neq \mu_{\text {SMR-FEB }} \neq \mu \text { SMR-MAR } \neq \mu_{\text {SMR-APR }} \neq \mu \text { SMR-MAY }
$$

Wilcoxon Signed Rank test has been conducted to investigate the significance of differences among stock market indicators during March, April and May 2020 compared with the January and February 2020. Table (4) indicates the monthly returns of GCC stock markets, as follows:

Table 4. Monthly returns of GCC stock markets

\begin{tabular}{|l|l|l|l|l|l|}
\hline \multicolumn{1}{|c|}{ Index } & \multicolumn{1}{|c|}{ Jan. 2020 } & \multicolumn{1}{c|}{ Fab. 2020 } & \multicolumn{1}{c|}{ Mar. 2020 } & Apr. 2020 & May 2020 \\
\hline SASEIDX & -0.01791 & -0.07497 & -0.14721 & 0.09339 & 0.01408 \\
\hline DFMGI & 0.00770 & -0.07182 & -0.31610 & 0.14413 & -0.04022 \\
\hline ADSMI & 0.01096 & -0.04941 & -0.23804 & 0.13272 & -0.02098 \\
\hline KWSEAS & 0.00677 & -0.11212 & -0.14123 & 0.03166 & 0.00406 \\
\hline MSM30 & 0.01853 & 0.01265 & -0.16525 & 0.02644 & 0.00145 \\
\hline BHSEASI & 0.02827 & 0.00172 & -0.18661 & -0.02953 & -0.03136 \\
\hline DSM & -0.00663 & -0.09116 & -0.13518 & 0.06784 & 0.00921 \\
\hline Mean & 0.00681 & -0.05502 & -0.18995 & 0.06666 & -0.00911 \\
\hline Std. Deviation & 0.01532 & 0.04668 & 0.06589 & 0.06215 & 0.02146 \\
\hline Minimum & -0.01791 & -0.11212 & -0.31610 & -0.02953 & -0.04022 \\
\hline Maximum & 0.02827 & 0.01265 & -0.13518 & 0.14413 & 0.01408 \\
\hline
\end{tabular}

When conducting Wilcoxon Signed Rank test, comparing the monthly return, results support the significance of difference between Feb., 2020 compared with Mar., 2020, with Z of -2.366 and sig. of 0.018, which means that the drop of monthly return from $-5.502 \%$ to $-18.995 \%$ is significant. So, for the first hypothesis, we can assume that there's a significant differences between monthly returns of GCC stock markets during Coronavirus spread compared with the earlier month.

The second hypothesis is about investigating the effect of each of "Coronavirus Cumulative Cases" (CCC), "New Coronavirus Cases" (NCC), "Cumulative Coronavirus Deaths" (CCD) and "New Coronavirus Deaths" (NCD) on "Stock Market Return" (SMR). Model (1) attempts to assess the effects of CCC model (2) concerns with investigating the effects of NCC. Besides, Model (3) investigates the effect of CCD and Model (4) is for NCD. 
Table 5. Effects of Coronavirus spread on stock market return using GMM technique

\begin{tabular}{l|c|c|c|c}
\hline \multicolumn{1}{c|}{ Variable } & Model (1) & Model (2) & Model (3) & Model (4) \\
\hline \multicolumn{1}{l|}{ Panel 5.1: For all period (March to May 2020) } & -0.012041 & 0.002411 & -0.0008973 & -0.000910 \\
\hline $\mathrm{C}$ & 0.001919 & & & \\
\hline Coronavirus Cumulative Cases & & -0.00666 & & \\
\hline Cumulative Coronavirus Deaths & & & 0.002704 & \\
\hline New Coronavirus Cases & & & $\mathbf{- 0 . 0 0 3 3 7 1}$ \\
\hline New Coronavirus Deaths & & & & \\
\hline $\mathrm{R}^{2}$ & 0.033091 & 0.002629 & 0.044752 & 0.020707 \\
\hline Durbin-Watson stat & 1.825751 & 1.931512 & 1.544919 & 1.519632 \\
\hline Obs. & 424 & 308 & 391 & 187 \\
\hline
\end{tabular}

Panel 5.2: For the first period (March 2020)

\begin{tabular}{l|c|c|c|c}
\hline $\mathrm{C}$ & -0.014484 & -0.005730 & -0.012036 & -0.017307 \\
\hline Coronavirus Cumulative Cases & 0.002180 & & & \\
\hline Cumulative Coronavirus Deaths & & -0.006077 & & \\
\hline New Coronavirus Cases & & & 0.006379 & \\
\hline New Coronavirus Deaths & & & & $\mathbf{- 0 . 0 1 0 0 5 3}$ \\
\hline $\mathrm{R}^{2}$ & 0.011495 & 0.051739 & 0.062865 & $\mathbf{0 . 3 0 7 3 9 3}$ \\
\hline Durbin-Watson stat & 1.896340 & 2.363424 & 1.720890 & 2.501683 \\
\hline Obs. & 145 & 32 & 113 & 113 \\
\hline
\end{tabular}

Panel 5.3: For the second period (April 2020)

\begin{tabular}{l|c|c|c|c}
\hline $\mathrm{C}$ & 0.002320 & 0.003242 & 0.001606 & 0.007743 \\
\hline Coronavirus Cumulative Cases & 0.000137 & & & \\
\hline Cumulative Coronavirus Deaths & & 0.000176 & & \\
\hline New Coronavirus Cases & & & 0.000452 & \\
\hline New Coronavirus Deaths & & & & 0.001365 \\
\hline $\mathrm{R}^{2}$ & 0.000062 & 0.000081 & 0.000612 & 0.001417 \\
\hline Durbin-Watson stat & 2.027149 & 2.038492 & 2.027071 & 1.432273 \\
\hline Obs. & 147 & 145 & 147 & 81 \\
\hline
\end{tabular}

Panel 5.4: For the third period (May 2020)

\begin{tabular}{l|c|c|c|c}
\hline $\mathrm{C}$ & -0.014206 & 0.001549 & -0.008577 & -0.000375 \\
\hline Coronavirus Cumulative Cases & 0.002189 & & & \\
\hline Cumulative Coronavirus Deaths & & -0.000212 & & \\
\hline New Coronavirus Cases & & & 0.002493 & \\
\hline New Coronavirus Deaths & & & & -0.002932 \\
\hline $\mathrm{R}^{2}$ & 0.037021 & 0.000269 & 0.034225 & 0.012999 \\
\hline Durbin-Watson stat & 1.761048 & 2.083964 & 1.533637 & 1.579637 \\
\hline Obs. & 321 & 240 & 294 & 139 \\
\hline Source: Outputs of & & & & \\
\hline
\end{tabular}

Source: outputs of data processing using EViews 10. 
For the whole period, results support the significance of New Coronavirus Deaths (NCD) effect on Stock Market Return (SMR) with explanation power of $2.1 \%$. Findings do NOT provide any significance of each of Coronavirus Cumulative Cases (CCC), New Coronavirus Cases (NCC) or Cumulative Coronavirus Deaths (CCD) effects on Stock Market Return (SMR). Regarding the problem of autocorrelation, Durbin-Watson test has been conducted and indicates that autocorrelation problem does not exist, as DW stat value is between 1 and 3.

When splitting the whole research period into 3 sub-periods, results support the effect of New Coronavirus Deaths (NCD) effect on Stock Market Return (SMR) with explanation power of $30.7 \%$ in March. $\mathrm{R}^{2}$ has been increased from $2.1 \%$ to $30.7 \%$ and this may be due to the homogeneity of the research period. Figure (3) shows that the decline of market indices has been continued till the end of March 2020, while curves seem to be more flattened in April and May. Stock markets of GCC countries seem to be different than those of China, France, Germany, and Spain, where stock market return seems to be sensitive to cumulative cases, not to new deaths.

So, for the first hypothesis, the null hypothesis is rejected and the alternative one could be accepted. However, for the second hypothesis, the null hypothesis could be accepted for CCC, NCC and CCD, while it's rejected for NCD. Figure (1) shows that the curves tend to be flattened starting from April 2020.

Results indicates that Stock Market Return (SMR) is sensitive only to New Coronavirus Deaths (NCD) in March. This may shed a light on the behavior of stock market in response to informational content regarding Coronavirus spread, where Coronavirus Cumulative Cases (CCC), New Coronavirus Cases (NCC) and Cumulative Coronavirus Deaths (CCD) haven't been considered as bad news. Besides, the effect of New Coronavirus Deaths (NCD) remains only during March.

\section{Robustness Checks}

A Robustness check has been conducted to investigate the country effect, where we consider the alternative hypothesis $\mathrm{Ha}: \beta \# 0$ versus null hypothesis $\mathrm{Hb}: \beta=0$, where $\beta$ is the regression coefficient of the following functions:

$$
\begin{aligned}
& \mathrm{SMR}=\alpha+\beta_{1} \mathrm{CCC}+\beta_{2} \mathrm{KSA}+\beta_{3} \mathrm{UAE}+\beta_{4} \mathrm{KUW}+\beta_{5} \mathrm{OMA}+\beta_{6} \mathrm{BAH}+\beta_{7} \mathrm{QAT} \\
& \mathrm{SMR}=\alpha+\beta_{1} \mathrm{NCC}+\beta_{2} \mathrm{KSA}+\beta_{3} \mathrm{UAE}+\beta_{4} \mathrm{KUW}+\beta_{5} \mathrm{OMA}+\beta_{6} \mathrm{BAH}+\beta_{7} \mathrm{QAT} \\
& \mathrm{SMR}=\alpha+\beta_{1} \mathrm{CCD}+\beta_{2} \mathrm{KSA}+\beta_{3} \mathrm{UAE}+\beta_{4} \mathrm{KUW}+\beta_{5} \mathrm{OMA}+\beta_{6} \mathrm{BAH}+\beta_{7} \mathrm{QAT} \\
& \mathrm{SMR}=\alpha+\beta_{1} \mathrm{NCD}+\beta_{2} \mathrm{KSA}+\beta_{3} \mathrm{UAE}+\beta_{4} \mathrm{KUW}+\beta_{5} \mathrm{OMA}+\beta_{6} \mathrm{BAH}+\beta_{7} \mathrm{QAT}
\end{aligned}
$$

Country effect has been considered, where KSA, UAE, KUW, OMA, BAH and QAT denote dummies of Saudi Arabia, United Arab Emirates, Kuwait, Oman, Bahrain and Qatar respectively. Results don't support any evidence about country effect of any of the above-shown dummies.

\begin{tabular}{|c|c|c|c|c|c|c|c|}
\hline Variable & $\begin{array}{c}\text { Excluding } \\
\text { KSA } \\
\end{array}$ & $\begin{array}{l}\text { Excluding } \\
\text { Abu Dhabi }\end{array}$ & $\begin{array}{c}\text { Excluding } \\
\text { Dubai }\end{array}$ & $\begin{array}{c}\text { Excluding } \\
\text { Kuwait } \\
\end{array}$ & $\begin{array}{c}\text { Excluding } \\
\text { Oman }\end{array}$ & $\begin{array}{c}\text { Excluding } \\
\text { Bahrain }\end{array}$ & $\begin{array}{c}\text { Excluding } \\
\text { Qatar } \\
\end{array}$ \\
\hline $\mathrm{C}$ & $\begin{array}{l}-0.014023 \\
(0.008997) \\
\end{array}$ & $\begin{array}{c}-0.014023 \\
(0.008997)\end{array}$ & $\begin{array}{r}-0.014728 \\
(0.01122) \\
\end{array}$ & $\begin{array}{c}-0.017307 \\
(0.010602) \\
\end{array}$ & $\begin{array}{l}-0.017307 \\
(0.010602) \\
\end{array}$ & $\begin{array}{c}-0.042595 \\
(0.02310) \\
\end{array}$ & $\begin{array}{r}-0.017307 \\
(0.01060) \\
\end{array}$ \\
\hline $\begin{array}{l}\text { New Coronavirus } \\
\text { Deaths }\end{array}$ & $\begin{array}{l}-0.008869 \\
(0.00397)^{*} \\
\end{array}$ & $\begin{array}{c}-0.008798 \\
(0.00385) * \\
\end{array}$ & $\begin{array}{l}-0.009479 \\
(0.00495) * \\
\end{array}$ & $\begin{array}{c}-0.01005 \\
(0.0048)^{*} \\
\end{array}$ & $\begin{array}{l}-0.01005 \\
(0.0047) * \\
\end{array}$ & $\begin{array}{l}-0.018816 \\
(0.00857)^{*} \\
\end{array}$ & $\begin{array}{l}-0.010056 \\
(0.0046) *\end{array}$ \\
\hline $\mathrm{R}^{2}$ & 0.384484 & 0.367514 & 0.31444 & 0.307393 & 0.317544 & 0.445413 & 0.327393 \\
\hline $\begin{array}{l}\text { Durbin-Watson } \\
\text { stat }\end{array}$ & 2.524390 & 2.677797 & 2.855646 & 2.701683 & 2.693549 & 2.094206 & 2.687036 \\
\hline Obs. & 10 & 10 & 10 & 12 & 12 & 8 & 12 \\
\hline
\end{tabular}

Another Robustness check has been conducted by reprocessing data after excluding only one stock market and provides the following results:

Table 6. Robustness check by excluding one stock market during March 2020 using GMM technique

Source: outputs of data processing using EViews 10. 
Results provide that stock markets of the GCC countries seem to be sensitive to Coronavirus spread measured by New Coronavirus Deaths (NCD). These effects haven't been confirmed supporting the rejecting of the null hypothesis of the second hypothesis, providing higher explanation powers; where $\mathrm{R}^{2}$ is $38.45 \%$ when excluding $\mathrm{KSA}$, is $36.75 \%$ for $\mathrm{ABD}$, is $31.44 \%$ for DUB, is $30.74 \%$ for $\mathrm{KUW}$, is $31.75 \%$ for OMA, is $44.5 \%$ for $\mathrm{BAH}$ and is $10.48 \%$ for QAT.

\section{Summary and Concluded Remarks}

This paper attempts to investigate the effects of 2020 Covid-19 world-wide spread on stock markets of GCC countries on daily basis over the period from March 1, 2020 till May 31, 2020. Coronavirus spread has been measured by cumulative cases, new cases, cumulative deaths and new deaths. Coronavirus spread has been measured by numbers per million of population, while stock market return is measured by $\Delta$ in stock market index.

Papers conducted in this topic tend to analyze Coronavirus spread in the highly infected countries and focus on the developed stock markets. Countries with low level of infection that have emerging financial markets seem to be less attractive to scholars concerning with Coronavirus spread on stock markets. This is why we try to investigate the GCC stock markets reaction to Covid-19 spread .

Findings show that there are significant differences among stock market indices during the research period. Besides, stock market returns seem to be sensitive to Coronavirus new deaths. Moreover, this has been confirmed for March with $\mathrm{R}^{2}$ of $30.7 \%$, without any evidence about these effects during April and May.

Results indicates that Stock Market Return (SMR) is sensitive only to New Coronavirus Deaths (NCD) in March. This may shed a light on the behavior of stock market in response to informational content regarding Coronavirus spread, where Coronavirus Cumulative Cases (CCC), New Coronavirus Cases (NCC) and Cumulative Coronavirus Deaths (CCD) haven't been considered as bad news. Besides, the effect of New Coronavirus Deaths (NCD) remains only during March.

\section{References}

Alber, N. (2013a). Industry Effect and Stock Market Reaction to Global Financial Crisis: A Comparative Analysis. Journal of Applied Finance and Banking, 3(3), 29-43.

Alber, N. (2013b). Competitive Advantages and Performance of Stock Market: The Case of Egypt. International Journal of Economics and Finance, 5(11), 133-144. https://doi.org/10.5539/ijef.v5n11p133

Alber, N. (2020a). The Effect of Coronavirus Spread on Stock Markets: The Case of the Worst 6 Countries (April 16). https://doi.org/10.2139/ssrn.3578080

Alber, N. (2020b). Finance in the Time of Coronavirus during 100 Days of Isolation: The Case of the European Stock Markets. (June 19). https://doi.org/10.2139/ssrn.3631517

Baldwin, R., \& Weder di Mauro, B. (2020). Economics in the Time of COVID-19. London: Centre for Economic Policy Research, CEPR Press.

Gormsen, N., \& Koijen, R. (2020). Coronavirus: Impact on Stock Prices and Growth Expectations. March 26, https://doi.org/10.3386/w27387

Kandil Goker, I., Eren, B., \& Karaca, S. (2020). The Impact of the COVID-19 (Coronavirus) on the Borsa Istanbul Sector Index Returns: An Event Study. Gaziantep University Journal of Social Sciences, Special Issue, 14-41

Liu, H., Manzoor, A., Wang, C., Zhang, L., \& Manzoor, Z. (2020). The COVID-19 Outbreak and Affected Countries Stock Markets Response. International Journal of Environmental Research and Public Health, 17(8), 1-19. https://doi.org/10.3390/ijerph17082800

Mazur, M., Dang, M., \& Vega, M. (2020). COVID-19 and March 2020 Stock Market Crash. Evidence from $S \& P 1500$. https://doi.org/10.2139/ssrn.3586603

McKibbin, W., \& Fernando, R. (2020). The Global Macroeconomic Impacts of COVID-19: Seven Scenarios. CAMA Working Paper 19/2020, Centre for Applied Macroeconomic Analysis CAMA, Australian National University. https://doi.org/10.2139/ssrn.3547729

Nanto, D. (2009). The Global Financial Crisis: Analysis and Policy Implications. Congressional Research Service, Retrieved from: www.crs.gov

Orlweski, L. (2008). Stages of the 2007/2008 Global Financial Crisis: Is There a Wandering Asset-Price Bubble? 
https://doi.org/10.2139/ssrn.1326649

Rehan, M., Alvi, J., \& Karaca, S. (2020). Short Term Stress of Covid-19 on World Major Stock Indices. https://doi.org/10.2139/ssrn.3663900

Saleh, A. (2017). Financing Microbusiness while Revisiting the Concepts of the "Providence State" and the Essence of "Entrepreneurship": An Applied Model on the UAE. The 24th International Academy of Management and Business (IAMB) Conference, (ISSN 1949-9108), Dubai, UAE, Retrieved from http://www.iamb.org/Proceedings/2017/dubai/MS/61\%20Saleh_MS.pdf

Yan, B., Stuart, L., Tu, A., \& Zhang, Q. (2020). Analysis of the Effect of COVID-19 on the Stock Market and Investing Strategies. https://doi.org/10.2139/ssrn.3563380

Yan, C. (2020). COVID-19 Outbreak and Stock Prices: Evidence from China. https://doi.org/10.2139/ssrn.3574374

\section{Copyrights}

Copyright for this article is retained by the author(s), with first publication rights granted to the journal.

This is an open-access article distributed under the terms and conditions of the Creative Commons Attribution license (http://creativecommons.org/licenses/by/4.0/). 